\title{
The Effectiveness of Speaking Instruction through Task-Based Language Teaching
}

\author{
Noor Malihah \\ English Department of Education Faculty \\ State Islamic Studies Institute (STAIN) of Salatiga \\ Jl. Tentara Pelajar No. 02 Salatiga 50721 Indonesia \\ noormalihah_itah@yahoo.com
}

\begin{abstract}
Speaking is a crucial part of second language learning and teaching. Teaching speaking is not merely to let students to repeat or memorize dialogues, but they should be able to use the utterance to communicate in the real situations. Teachers' attitudes to respond the students thought and opinion is important, as they should not be forced to speak and put them in the deep anxiety, but we invite the learners to use any languages in the performance of oral tasks where teachers give a task and learners complete the task. Teachers should be able to create such situations where students hold meaningful tasks that will promote their speaking proficiency. This can be realized when students works with their friends in groups to complete a task. Task-Based approach is the alternate to solve the problem where learning is developed through performing a series of activities as steps towards successful task realization.
\end{abstract}

Key words: Language learning and teaching, speaking instruction, taskbased approach, task 


\section{Introduction}

Developing interactive teaching strategy is very essential in creating meaningful communication. The traditional approaches of language teaching (Grammar Translation, Direct Method, and Audiolingual Method) try to manage the language learning process, which focus much on a controlled, measured practicing of language items where teacher is very much in charge. On the other way around, the communicative approach focuses more on language learning as interaction, and meaningful communication becomes the main point rather than the complexity of grammar rules. This approach will lead the students to talk more during the class and outside the class in many activities like to talk about themselves, to have a joke, to give an idea, without thinking whether the structure is correct or incorrect as they have fun in English class.

Among the four language skills, learners consider speaking as the most difficult one since it needs great courage as well as preparation to produce the language. Their personalities play a large role in determining how quickly and how correctly they will accomplish this skill. Those who are risk-takers unafraid of making mistakes will generally be more talkative, but they do not realize with the errors they make. Meanwhile, the conservative, shy students may take a long time to speak confidently, but when they do, they will make fewer errors and be proud of their English ability. Learners will think about which one is better, to talk much with many errors or to think more with better result. It can be answered when the aims of speaking is clearly stated, that is to build meaningful communication. In this case, to encourage learners to talk as much as possible to convey the messages of communication is more important rather than to let them think about the grammar rules they use.

When we talk about speaking, we intend the learners to use any languages in the performance of oral tasks where teachers give a task and learners complete the task. Harmer (1988: 87-88) proposed the reason 
why it is a good idea to give students speaking tasks. They are: 1) Rehearsal: when students have free discussions or conversations inside the classroom they have a chance to rehearse having discussions or conversations outside the classroom; 2) Feedback: engagement in a speaking task which demands for the use of all and any language at the students' command provides feedback for both teacher and students; 3 ) Engagement: completing a speaking task can be really motivating and give real satisfaction.

There is a phenomenon today that students are sometimes not motivated to talk because they are lack involvement in the topic. Besides, many students have to overcome a psychological constraints before they are prepared to speak in the foreign language. Some students feel uneasy when they have to speak in the classroom situation because there is always an audience. A few prefer not to speak at all and deny opportunities for practice. They feel so anxious in practicing their speaking skill in foreign language.

People learning a foreign language is afraid of such a comment: "I hate make a fool of myself". Students sometimes feel foolish because they use their native language beyond their consciousness. So, how can teachers reduce their fear of looking foolish and build up their confidence and pleasure in using English? How can teachers convict them to control their talk while speaking in English? There should be therefore an appropriate approach implemented in the process of teaching learning speaking.

One alternate approach, which is possible to implement for the sake of enhancing the students' confidence of speaking is the task-based approach. Using task-based approach, each student should get the same opportunity to experience the learning process by putting him/her in a situation in which she/he can decide alone, mainly the way of expressing and accepting experience of using the target language. It is expected that 
the implementation of this approach in speaking class will change the condition happened in this class where some students dominate the opportunity of talking over the other ones.

\section{Discussion}

\section{Speaking}

Speaking skill is an ability to orally express opinion, thought, and feeling to other people both directly and indirectly. Moris in Novia (2002) states that speaking is the novice means of communication among member of society in expressing their thought and is as the representation of social behavior. On the other way around, Wilkin in Maulida (2001) proposes that the aim of the recent teaching English as FL is speaking achievement. Furthermore, in Oktarina (2002) she underlines that speaking skill is the ability of arranging sentences since communication happens through the series of sentences constructing in performing the various behavior from various society. In a bit different statement, Chaney (1998: 13) states that speaking is the process of building and sharing meaning through the use of verbal and non-verbal symbols, in a variety of contexts.

From the above definition, it can be concluded that speaking is a crucial part of second language learning and teaching. Dealing with the importance of speaking in EFL, Stovall (1998) states that language learners need to recognize that speaking involves three areas of knowledge:

1. Mechanics (pronunciation, grammar, and vocabulary): Using the right words in the right order with the correct pronunciation

2. Functions (transaction and interaction): Knowing when clarity of message is essential (transaction/information exchange) and when precise understanding is not required (interaction/relationship building).

3. Social and cultural rules and norms (turn-taking, rate of speech, length of pauses between speakers, relative roles of participants): 
Understanding how to take into account who is speaking to whom, in what circumstances, about what, and for what reason.

\section{Teaching speaking}

Nunan (2003) defines the meaning of "teaching speaking" as teaching ESL learners to (1) Produce the English speech sounds and sound patterns; (2) Use word and sentence stress, intonation patterns and the rhythm of the second language; (3) Select appropriate words and sentences according to the proper social setting, audience, situation and subject matter; (4) Organize their thoughts in a meaningful and logical sequence; (5) Use language as a means of expressing values and judgments; (6) Use the language quickly and confidently with few unnatural pauses, which is called as fluency.

On the other way around, many times ago, teaching speaking has been undervalued and English language teachers teach speaking just in the forms of a repetition of drills or memorization of dialogues. It should be now extended that the goal of teaching speaking is not merely to force them to speak the English utterances but it should cover the mastery of students' communicative skills due to the fact that only in that way, students can express themselves and learn how to follow the social and cultural rules appropriate in each communicative circumstance.

To do so, learners should be given an opportunity to work in interactive mode to talk about themselves in personally relevant ways. This demands such new dimension to the language learning process.

\section{Anxiety}

The students should feel comfortable in sharing their feeling and opinions even some cultures consider it as improper values to talk about one. Teachers' attitudes to respond the students thought and opinion is also important as they should not be forced to speak, they should be heard 
and respected, and they should extend the same courtesy to their classmates. Teachers should realize that students many times live in difficult conditions, and as a consequence, teachers should avoid expressions of negative feelings. Such attitude is expected to reduce the student anxiety of making mistakes and they will have courageous to speak.

Anxiety, simply speaking, is a kind of troubled feeling in the mind. It is a subjective feeling of tension, apprehension, nervousness, and worry associated with an arousal of the automatic nervous system (Horwitz, 1986).

Krashen (1985a, 1985b) maintained that anxiety inhibits the learner's ability to process incoming language and short-circuits the process of acquisition. An interaction is often found among anxiety, task difficulty, and ability, which interferes at the input, processing, retrieval, and at the output level. If anxiety impairs cognitive function, students who are anxious may learn less and also may not be able to demonstrate what they have learned.

Furthermore, Crookall and Oxford (1991) reported that serious language anxiety may cause other related problems with self-esteem, selfconfidence, and risk-taking ability, and ultimately hampers proficiency in the second language.

MacIntyre and Gardner (1991) found that speaking is by far the main agent of anxiety-arousal, and that students with high anxiety perform worse than those with low anxiety.

According to Young (1991), there are six potential causes of language anxiety that include personal and interpersonal, learner beliefs about language learning, instructor beliefs about language teaching, instructor-learner interactions, classroom procedures and language tests. However, to date, findings by Horwitz, Horwitz and Cope (1986) have been the most influential. They identified three causes of language anxiety, that is, communication apprehension, test anxiety, and fear of negative evaluation. 
Based on the above definition, anxiety is a kind of troubled feeling in the mind, which covers a subjective feeling of tension, apprehension, nervousness, and worry associated with an arousal of the automatic nervous system. There are three causes of anxiety; they are (1) communication apprehension, (2) the test, and (3) the fear of making mistakes in producing the language.

\section{Task based language teaching}

Richards (2001: 223) states that Task-Based Language Teaching (TBLT) refers to an approach based on the use of tasks as the core unit of planning and instruction in language teaching. TBLT proposes the notion of 'task' as a central unit of planning and teaching. Task-based syllabus design has interested some researchers and curriculum developers in second/foreign language instruction since the mid-1980s (Long 1985; Breen 1987; Prabhu 1987; Nunan 1989 in Ahmed, 1996), as a result of widespread interest in the functional views of language and communicative language teaching. The variety of students' backgrounds of experience leads to the types and the arrangement of activities in taking the practice opportunities as well as the attraction of having the group interaction, naturally, closely, freely, happily.

Giyoto (2007) also states that TBLT seems to have a variety of features that are helpful in the development of language proficiency. The language is initially presented in context through dialogues that are local culturally based. Such texts based on everyday life give students' models that can be used to develop functional proficiency through role-taking and their interactive language practice activities.

Task-based language education starts from the basic idea that students learn a language by performing tasks. A task is generally described as an activity in which people engage to attain an objective, and which involves the meaningful use of language (Bygate, Skehan \& Swain, 2002; 
Long, 1985; Van den Branden, 2006). In the above-mentioned example, it turned out that the task that was used, and which was taken from a brand new task-based syllabus, was not perceived as a "task" by the students at all. For them, it did not involve meaningful use of language, nor did it give rise to the kind of activity in which people engage to attain an objective they find worthwhile.

Bystrom (2007) mentioned that task is usually seen as a purposeful set of linked concrete or cognitive activities performed by people (or machines); normally, it has a meaningful purpose as well as an identifiable beginning and end. This kind of task is viewed as a dynamic activity, rather than a stable description. Task seen from the latter point of view is a description of what is expected from a person (or a machine), such as "make a personnel allocation plan for the next four weeks". Task often includes some type of requirement (for instance, in respect to duration or quality of performance or other issues of concern), and it may be either set by the task performer himself or by others. Similarly, task may be initiated by the task performers themselves or assigned by others as well as performed in solitude or as a team effort. Task takes place both within and outside work. Task may be authentic or simulated and performed in authentic or simulated contexts. To summarize, task are multidimensional activities.

Ellis (2003: 16) provides a composite definition:

A task is a workplan that requires learners to process language pragmatically in order to achieve an outcome that can be evaluated in terms of whether the correct or appropriate propositional content has been conveyed. To this end, it requires them to give primary attention to meaning and to make use of their own linguistic resources, although the design of the task may predispose them to choose particular forms. A task is intended to result in language use that bears a resemblance, direct or indirect, to the way language is used in the real world. Like other language activities, a task can 
engage productive or receptive, and oral or written skills, and also various cognitive processes.

An interesting aspect of this definition is that it includes almost all the major points of contention in language pedagogy: attention to meaning, engagement with grammar, inclusion of pragmatic properties, use of authentic communication, importance of social interaction, integration of language skills, and the connection to psycholinguistic processes.

\section{The implementation of task-based approach in the speaking instruction}

ESL/FL teachers and some linguists now agree that interaction while the students learn a second/foreign language is very important. It means what they need during the learning process is the communicative language teaching approach where collaborations among members is part essential as well. In this case the learning process should be arranged in real-life situations that require communication. It is expected that students will have the opportunity to communicate each other in the target language. Thus, teachers should be able to create such situations where students hold meaningful tasks that will promote their speaking proficiency. This can be realized when students works with their friends in groups to complete a task.

In Task-Based approach, learning is developed through performing a series of activities as steps towards successful task realization. By working towards task realization, the language is used immediately in the real-world context of the learner, making learning authentic. This approach puts the task to be completed during the language learning process. Problems are given to learners to be solved using the target language as a task to be completed individually or collaboratively. The teacher facilitates the language needed to succeed the task. In this case traditional teacher-centered approach is thrown away since this approach will let the learners to be active in seeking the appropriate forms and in 
practicing the language skills so that they will more confident with their own works.

Willis (1996) broke the task completion into three sections. The pre-task, the task cycle, and the language focus. The elaboration is as follow:

\section{Pre-task}

In the pre-task, the teacher will present what will be expected of the students in the task phase. Additionally, the teacher may prime the students with key vocabulary or grammatical constructs, although, in "pure" task-based learning lessons, these will be presented as suggestions and the students would be encouraged to use what they are comfortable with in order to complete the task. The instructor may also present a model of the task by either doing it themselves or by presenting picture, audio, or video demonstrating the task.

\section{Task Cycle}

During the task phase, the students perform the task, typically in small groups, although this is dependent on the type of activity. And unless the teacher plays a particular role in the task, then the teacher's role is typically limited to one of an observer or counselor - thus the reason for it being a more student-centered methodology.

\section{a. Planning}

Having completed the task, the students prepare either a written or oral report to present to the class. The instructor takes questions and otherwise simply monitors the students.

b. Report

The students then present this information to the rest of the class. Here the teacher may provide written or oral feedback, as appropriate, and the students observing may do the same. 


\section{Language Focus}

In focusing the language produced by students, the teachers will create two stages here, they are:

a. Analysis

Here the focus returns to the teacher who reviews what happened in the task, in regards to language. It may include language forms that the students were using, problems that students had, and perhaps forms that need to be covered more or were not used enough.

b. Practice

The practice stage may be used to cover material mentioned by the teacher in the analysis stage. It is an opportunity for the teacher to emphasize key language.

Within the sections above, learners will complete the task through preparation where in this case they will reduce their troubled feeling in mind or anxiety. They have more time to think how to complete the task in their best way. It is then expected that learners will not be nervous and full of tension in performing their speaking ability. Through TBLL, focus on form is not the main point instead of focus in meaning. Due to the fact, learners will not be afraid of making mistakes on the series of complicated rules which is very probable to pressure them in performing their speaking ability.

Besides, TBLL is also defined as learning by doing mostly in group work which allows discussion and help between learners. The role of teacher in task-centered learning is that of a wise and experienced member of the group. Willis (1998) says that at the end of a workshop on using task-based approach to language teaching teachers commented that "taskbased learning is like an adventure-learners surprise you by coming up with all kind of things". She accepts that TBLL may entail elements of 
risk that can make things quite scary for teachers and offers a principled use of a task-based learning framework in order to show how to minimize such a risk and to help teachers create tasks that will prove fulfilling and challenging but not too risky.

Moor (1998b) states that worthwhile task-based activities should have the following characteristics:

1. Intrinsic interest (personal anecdotes, favorite stories, discussions where there is a problem to be resolved, etc.)

2. The existence of an outcome or end product (records, videos, posters, etc.)

3. Provision for language input (from the teacher, reference books and fellow students, etc.)

4. Opportunities for silence, spontaneous speech and prepared speech (time for planning)

\section{The example of task-based approach in speaking instruction}

The above cycles can be seen in the action below, which is taken from Frost (2002) but has been modified.

\section{Preparation and materials}

You will need to record two people planning a night out on the town.

During the class, the task is divided into three phases: pre-task, during-task, and post-task. First, it concerns with the various activities that teachers and students should do before they start the task, such as whether students are given issue of the story, time allotted to plan the performance of the task.

Pre-task (15-20min)

Aim: To introduce the topic of nights out and to give the class exposure to language related to it. To highlight words and phrases, 
a. Show students pictures of a night out in a restaurant / bar and ask them where they go to have a good night out.

b. Brainstorm words/phrases onto the board related to the topic; people / verbs / feelings etc.

c. Introduce the example of conversation of two people planning a night out. Write up different alternatives on the board to give them a reason for listening e.g. (a) restaurant / bar (b) meet at the train station / in the square.

d. Tell them that they are going to plan a class night out and give them a few minutes to think it over.

The second phase, the 'during task' phase, centres on around the task itself and affords task of experiencing the various communicative ways of sharing ideas or options, including the students that are required to operate under time-pressure or not and complete ideas of their story. The final phase is 'post-task' and involves procedures for following up on the task performance. Only the 'during task' phase is obligatory in task-based teaching (Ahmed, 1996).

\section{Task (10min)}

- Students do the task in twos and plan the night. Match them with another pair to discuss their ideas and any similarities and differences.

\section{Planning (10min)}

- Each pair rehearses presenting their night out. Teacher walks around, helps them if they need it and notes down any language points to be highlighted later.

Report (15 $\mathrm{min})$

a. Class listen to the plans, their task is to choose one of them. They can ask questions after the presentation. 
b. Teacher gives feedback on the content and quickly reviews what was suggested. Students vote and choose one of the nights out.

The final phase is 'post-task' and involves procedures for following up on the task performance. Only the 'during task' phase is obligatory in task-based teaching

\section{Language Focus (20min)}

a. Write on the board fives good phrases used by the students during the task and five incorrect phrases/sentences from the task without the word that caused the problem. Students discuss the meaning and how to complete the sentences.

b. Hand out the example of conversation and ask the students to underline the useful words and phrases.

c. Highlight any language you wish to draw attention to e.g. language for making suggestions, collocations etc.

d. Students write down any other language they wish to remember.

Thus, minimally, a task-based lesson concentrates the students' preparation, performance of a task. The pre-task can serve a crucial role in ensuring that the task performance is maximally effective for language. The analysis of the task can be graded for the very first start of studying English in the university to the fluent use and instant use of the language.

It is said communicative when the better the speaker and the audience knows each other; the more effective the message will be related. The speaker and the audience know certain things and share mutually. Furthermore, at a theoretical level, it has become more clear that oral communication skills (i.e., speaking) are complex sociolinguistic phenomena (Hymes in Ahmed, 1996), and that the classroom situation is not only determined by curricular and pedagogical concerns but also has social and personal dimensions. 
The focus of discussion in task-based language teaching is the rich complexity of task as the unit of analysis, the classroom situation and the institutional contexts need to be incorporated. The class is divided into many groups depending on the time allotment and also the number of the students. The number of the members for one group and the numbers of the group depend on how long every student should experience the task. The length of the time of each group is the same as the length of the English class because the groups of the class do the task simultaneously at the same time. When the English class is 100 minutes, every group of the class also gets 100 minutes, and if the group is of five students, every student will have from 10 to 20 minutes for experiencing the use of the language or doing his task.

\section{Conclusion}

\section{Advantages}

Task-based learning is advantageous to the student because it is more student-centered, allows for more meaningful communication. Although the teacher may present language in the pre-task, the students are ultimately free to use what grammar constructs and vocabulary they want. This allows them to use all the language they know and are learning, rather than just the 'target language' of the lesson. Furthermore, as the tasks are likely to be familiar to the students (e.g.: buying a ticket), students are more likely to be engaged, which may further motivate them in their language learning.

\section{Disadvantages}

There have been criticisms that task-based learning is not appropriate as the foundation of a class for beginning students. Others claim that students are only exposed to certain forms of language, and are being neglected of others, such as discussion or debate. Teachers 
may want to keep these in mind when designing a task-based learning lesson plan.

\section{References:}

Ahmed, M.K.1996. Teaching oral communication skills in academic settings: A case study in task-based approach to syllabus design. Presented at Thai TESOL $16^{\text {th }}$ Annual Convention, Pataya, Thailand

Byström, Katriina. 2007. Approaches to "task" in contemporary information studies. Sweden: Swedish School of Library and Information Science

Giyoto. 2007. Task-Based Approach Of Facilitating The Speaking Practice For A Big Class (From the bravery of being wrong to the pride of being acceptable). A paper presented in TEFLIN 2007

Krashen, S. D. 1985a. Applications of psycholinguistic research to the classroom. In C. James (Ed.), Practical applications of research in foreign language teaching (pp.51-66). Lincolnwood, IL: National Textbook Co.

Madya, Suwarsih, 2007. Penelitian Tindakan Kelas. http:// www.ktiguru.org/index.php/ptk-1.

Novia, T. 2002. Strategy to improve student's ability in speaking. Makalah Tugas Akhir S1. Padang: UNP Padang.

Nurkamto, Joko. 2002. An introduction to classroom action research. A paper presented in MGMP Bahasa Inggris Madrasah Aliyah seJawa Tengah in Madrasah Aliyah Negeri Model Magelang Jawa Tengah. 
Octarina, D. 2001. Interactive activities as the way to improve EFL learners'speaking abilities. Makalah Tugas Akhir S1 - Padang: UNP Padang

Peace Corps (Information Collection and Exchange). 1989. English as a Second or Foreign Language. http://www.peacecorps.gov

Richards, J., \& Rodgers, T. 2001. Approaches and methods in language Teaching (2nd ed.). Cambridge: Cambridge University Press.

Rodgers, T. 2001. Language Teaching Methodology. Digests (paper), Hawaii. University of Hawaii

Rod Ellis. 2006. Asian EFL Journal - Conference 2006. University of Auckland http://asian-efl-journal.com/Ellis_Task_based_ teaching.doc;

Willis, J. 1996. A framework for task-based learning. Harlow, U.K. Longman: Addison- Wesley.

Chaney, 1998. p. 13. in http://unr.edu/homepage/hayriyek

Stovall. 1998, in http://www.nclrc.org/essentials/speaking/spindex.htm http://InformationR.net/ir/12-1/colis/colis26.html 